\title{
A METHOD FOR THE DETERMINATION OF GLUTAMINE IN CEREBROSPINAL FLUID AND THE RESULTS IN HEPATIC COMA
}

\author{
BY \\ T. P. WHITEHEAD AND S. R. F. WHITTAKER \\ From the Group Pathological Laboratory and the Medical Unit, Warwick Hospital
}

(RECEIVED FOR PUblication AUgUST 10, 1954)

The free amino-acids normally present in cerebrospinal fluid are leucine, valine, alanine, glycine, serine, and glutamine. The concentration of each amino-acid is much less than that found in plasma, with the exception of glutamine, which is in higher concentration in the cerebrospinal fluid. Walshe (1951) examined the cerebrospinal fluid of three patients in hepatic coma by paper chromatography and found an excess of glutamine. This important observation suggested that if a simple method for the quantitative determination of the glutamine content of the cerebrospinal fluid could be developed, such an estimation might prove valuable in the differential diagnosis of cases of hepatic coma.

\section{Material}

Hepatic Coma. - Cerebrospinal fluids were obtained from seven patients in hepatic coma. Brief clinical histories follow and the more usual liver function tests are shown in the Table.

Case 1.-A boy aged 11 had acute necrosis of the liver following an attack of infective hepatitis nine weeks before. A period of coma lasting for $\mathbf{4 8}$ hours occurred 12 days before death. He recovered consciousness, and his general condition improved following energetic treatment with electrolyte solutions and glutamic acid, but he died suddenly 10 days later. Necropsy was performed.

Case 2.-A man aged 31 had cirrhosis of the liver following an attack of infective hepatitis three years before. He had signs of portal hypertension with oesophageal varices. He was admitted to hospital following repeated haematemeses and became disorientated and violent. He lapsed into deep coma for four days but recovered following treatment with glutamic acid, and is in fair health and at work 18 months later.

Case 3.-A boy aged 12 had glycogen disease with secondary cirrhosis of the liver (biopsy performed). He had been in and out of hospital on several occasions for investigation and paracentesis abdominis.
While being nursed at home he became disorientated and restless and was readmitted to hospital in a stuporose condition. He died in deep coma four days later.

Case 4.-A woman aged 32 had acute necrosis of the liver following a fulminating attack of infective hepatitis three weeks before. She became restless, incoherent, and then alternated between violent delirium and stupor. Finally she lapsed into deep coma and died two days later. Necropsy was performed.

Case 5.-A woman aged 27 had acute necrosis of the liver following an attack of infective hepatitis three months before. She also had a history of jaundice at the age of 9. During the terminal stage of the illness she became disorientated and lapsed in and out of coma. Necropsy was performed.

Case 6.-A woman aged 63 had cirrhosis of the liver of unknown aetiology. She had a history of several attacks of coma with moderate health between attacks, but no history of haematemesis but frequent epistaxes and blood loss from haemorrhoids. She was admitted to hospital in a confused state and later became comatose. She recovered sufficiently to leave hospital but died six months later. Necropsy was performed.

Case 7.-A man aged 60 had cirrhosis of the liver with terminal mesenteric thrombosis. He had been in hospital on several occasions for paracentesis abdominis and was finally readmitted on account of abdominal pain and vomiting. He became comatose and died. Necropsy was performed.

Cirrhosis of the Liver.-Cerebrospinal fluids were obtained from nine cases of cirrhosis of the liver with evidence of liver damage. The more conventional liver function tests are shown in the Table.

Control Cases.-Cerebrospinal fluids were obtained from 31 patients in whom no disease of the liver was suspected or found. Five patients were in coma caused by non-hepatic conditions, five were suffering from meningitis, three from haemat- 
TABLE

RESULTS OF LIVER FUNCTION TESTS AND CEREBROSPINAL FLUID GLUTAMINE LEVELS IN HEPATIC DISEASE

\begin{tabular}{|c|c|c|c|c|c|c|c|c|c|}
\hline \multirow{2}{*}{$\begin{array}{l}\text { Case } \\
\text { No. }\end{array}$} & \multirow{2}{*}{ Sex } & \multirow{2}{*}{$\begin{array}{c}\text { Age } \\
\text { (Years) }\end{array}$} & \multirow{2}{*}{$\underset{\substack{\text { Serum } \\
\text { Bilirubin } \\
\text { (mg./100 ml.) }}}{\text { mg. }}$} & \multirow{2}{*}{$\begin{array}{c}\text { Thymol } \\
\text { Turbidity } \\
\text { (Units } 100 \mathrm{ml} .)\end{array}$} & \multirow{2}{*}{$\begin{array}{c}\text { Alkaline } \\
\text { Phosphatase } \\
\text { (K.A. Units } 100 \mathrm{ml} \text {.) }\end{array}$} & \multicolumn{3}{|c|}{ Serum Proteins (g./100 ml.) } & \multirow{2}{*}{$\begin{array}{l}\text { C.S.F. } \\
\text { Glutamine } \\
(\mathrm{mg} .100 \mathrm{ml} .)\end{array}$} \\
\hline & & & & & & Total & Albumin & Globulin & \\
\hline $\begin{array}{c}\text { Hepat } \\
1 \\
2 \\
3 \\
4 \\
5 \\
6 \\
7\end{array}$ & $\begin{array}{c}m a \\
\mathbf{M} \\
\mathbf{M} \\
\mathbf{M} \\
\mathbf{F} \\
\mathbf{F} \\
\mathbf{F} \\
\mathbf{M}\end{array}$ & $\begin{array}{l}11 \\
31 \\
12 \\
32 \\
27 \\
63 \\
60\end{array}$ & $\begin{array}{r}17.0 \\
1.5 \\
7.2 \\
39.0 \\
9.0 \\
3.4 \\
3.5\end{array}$ & $\begin{array}{r}18 \\
8 \\
2 \\
5 \\
3 \\
18 \\
5\end{array}$ & $\begin{array}{c}14 \\
17 \\
56 \\
9 \\
21 \\
27 \\
7 \cdot 8\end{array}$ & $\begin{array}{l}6 \cdot 4 \\
5 \cdot 1 \\
6 \cdot 0 \\
7 \cdot 5 \\
8 \cdot 1 \\
5 \cdot 0 \\
7 \cdot 1\end{array}$ & $\begin{array}{l}1 \cdot 3 \\
2 \cdot 1 \\
1 \cdot 1 \\
4 \cdot 4 \\
2 \cdot 6 \\
2 \cdot 2 \\
3 \cdot 3\end{array}$ & $\begin{array}{l}5 \cdot 1 \\
3 \cdot 0 \\
4 \cdot 9 \\
3 \cdot 1 \\
5 \cdot 5 \\
2 \cdot 8 \\
3 \cdot 8\end{array}$ & $\begin{array}{l}54 \\
35 \\
54 \\
30 \\
30 \\
43 \\
33\end{array}$ \\
\hline $\begin{array}{c}\text { Cirrho } \\
8 \\
9 \\
10 \\
11 \\
12 \\
13\end{array}$ & $\begin{array}{c}\text { f the } \\
\mathbf{F} \\
\mathbf{M} \\
\mathbf{M} \\
\mathbf{F} \\
\mathbf{M} \\
\mathbf{M}\end{array}$ & $\begin{array}{l}42 \\
72 \\
77 \\
45 \\
61 \\
61\end{array}$ & $\begin{array}{l}6 \cdot 4 \\
9 \cdot 5 \\
1.8 \\
2 \cdot 3 \\
1 \cdot 5 \\
2 \cdot 6\end{array}$ & $\begin{array}{r}18 \\
7 \\
5 \\
4 \\
9\end{array}$ & $\begin{array}{c}6 \cdot 5 \\
30 \\
20 \\
8 \\
11 \\
9\end{array}$ & $\begin{array}{l}6 \cdot 1 \\
5 \cdot 5 \\
5 \cdot 0 \\
5 \cdot 8 \\
5 \cdot 5 \\
7 \cdot 6\end{array}$ & $\begin{array}{l}2 \cdot 3 \\
1 \cdot 4 \\
2 \cdot 2 \\
2 \cdot 0 \\
1 \cdot 7 \\
3 \cdot 5\end{array}$ & $\begin{array}{l}3 \cdot 8 \\
4 \cdot 1 \\
2 \cdot 8 \\
3 \cdot 8 \\
3 \cdot 8 \\
4 \cdot 1\end{array}$ & $\begin{array}{l}21 \\
27 \\
20 \\
23 \\
16 \\
22\end{array}$ \\
\hline
\end{tabular}

emesis due to peptic ulceration, and the remaining 18 from conditions in which lumbar puncture was a justifiable investigation.

\section{Methods}

No special precautions were taken in the collection of the cerebrospinal fluids. Analysis was usually performed on the day of collection, otherwise the fluid was frozen and kept in an ice chamber.

Chromatography.-The one-dimensional, circular paper technique of Giri and Rao (1952) has been used. For successful chromatography of the aminoacids in cerebrospinal fluid the fluid must be electrolyte- and protein-free. This is accomplished most simply by using a cation ion-exchange resin as described in a preliminary communication by Prior and Whitehead (1953).

The resin (Zeo Karb 225) is activated by mixing with twice its volume of $10 \mathrm{w} / \mathrm{v} \%$ hydrochloric acid and allowing to stand for approximately two hours. The resin is then washed free of acid with distilled water and placed in a column $15 \mathrm{~cm} . \times 0.5 \mathrm{~cm}$., when $1 \mathrm{ml}$. of cerebrospinal fluid is passed through the column and $15 \mathrm{ml}$. of water used to wash it through. The resin retains cations and amino-acids; anions and protein pass through the column unchanged. The amino-acids are then displaced from the column by $15 \mathrm{ml}$. of $\mathrm{N} / 1$ ammonia solution, the cations remaining on the column. The first $3 \mathrm{ml}$. of eluate is discarded, the next $12 \mathrm{ml}$. is collected and evaporated under reduced pressure at $37^{\circ} \mathrm{C}$. The dried residue is redissolved in $1 \mathrm{ml}$. of distilled water and the resulting solution used for chromatography. (Two amino-acids, which are not normally encountered in cerebrospinal fluid, are lost in this technique ; taurine is not retained on the column, arginine needs a stronger ammonia solution for elution.) For chromatography $20 \mathrm{c} . \mathrm{mm}$. $(2 \times 10 \mathrm{c} . \mathrm{mm}$. $)$ of the resulting solution is used. The solvent used is a butyl alcohol:acetic acid!water mixture. The papers are developed in the usual way with ninhydrin.
Assay of Glutamine.-Glutamine is completely hydrolysed to glutamic acid and ammonia by dilute acid at $100^{\circ} \mathrm{C}$. The only other substance encountered in cerebrospinal fluid that produces ammonia under these conditions is urea. Other amino-acids, asparagine, protein, and glucosamine, even in relatively large amounts, are not hydrolysed. We have used acid hydrolysis to ammonia as a method of assaying the glutamine content of cerebrospinal fluid.

To $1 \mathrm{ml}$. of cerebrospinal fluid in a $12 \mathrm{ml}$. test tube, $0.2 \mathrm{ml}$. of $10 \mathrm{v} / \mathrm{v} \%$ sulphuric acid is added. The tube is placed in a boiling water bath for exactly 10 minutes, removed, and cooled in cold water, when $0.3 \mathrm{ml}$. of $10 \mathrm{w} / \mathrm{v} \%$ sodium hydroxide is added followed by $5 \mathrm{ml}$. of water, $0.5 \mathrm{ml}$. of $2 \%$ gum ghatti solution, $2 \mathrm{ml}$. of Nessler's reagent, and the colour immediately read in a colorimeter using a blue-green filter. A standard solution of glutamine $(25 \mathrm{mg}$./ $100 \mathrm{ml}$.) is similarly treated. A blank determination performed in exactly the same manner but omitting the boiling may be performed, but this is unnecessary if the fluid is examined on the day of collection. The standard glutamine solution should be prepared on the day of analysis. Urea is partially hydrolysed under these conditions, and therefore the urea concentration of the fluid is also determined and a correction made. The hydrolysis of urea at concentrations up to $400 \mathrm{mg} . / 100 \mathrm{ml}$. is $1 \%$, so that the correction is urea concentration (mg./100 ml.) $\times \frac{5}{100} \mathrm{mg}$. "glutamine" $/ 100 \mathrm{ml}^{*}$ The correction is usually less than $2 \mathrm{mg} . / 100 \mathrm{ml}$. The highest urea concentration encountered in this investigation was $73 \mathrm{mg}$./ $100 \mathrm{ml}$, entailing a correction of $3.6 \mathrm{mg} . / 100 \mathrm{ml}$. in a fluid containing $57 \mathrm{mg}$. glutamine $/ 100 \mathrm{ml}$.

* Each mg. of urea yields $\frac{28}{60 \times 100}=0.0047 \mathrm{mg}$. of nitrogen. One mg. of glutamine yields $\frac{14}{146}=0.096 \mathrm{mg}$. of nitrogen, so that the factor for urea correction is $\frac{0.0047}{0.096}=0.05$ (or $\left.\frac{5}{100}\right)$. 


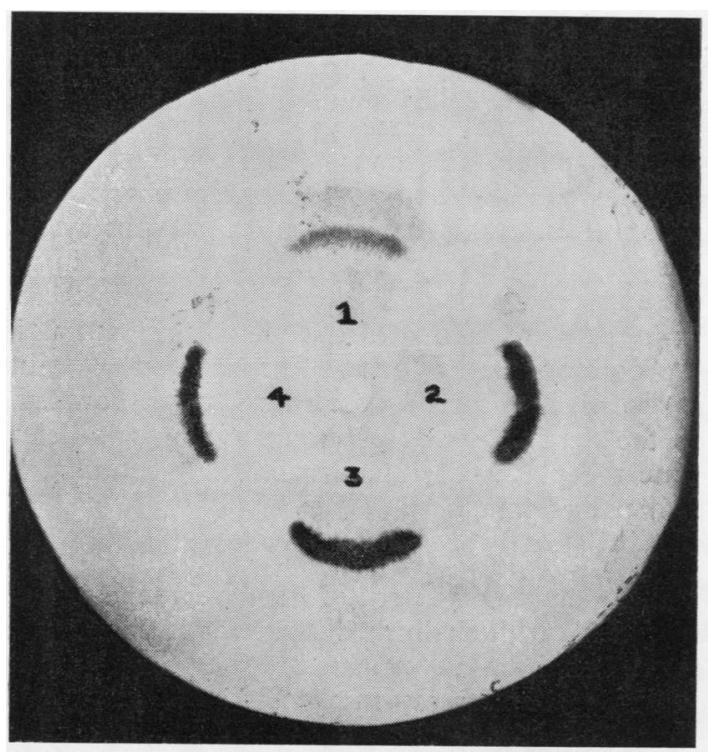

FIG. 1.-Paper chromatography of cerebrospinal fluids from normal control (1), hepatic comas (2) and (3), and cirrhosis of the liver (4).

\section{Results}

Chromatography.-With the technique described above, using $20 \mathrm{c} . \mathrm{mm}$. of cerebrospinal fluid for chromatography, normal fluids usually show one band, that due to glutamine. To demonstrate the presence of other amino-acids larger quantities of fluids are required. The purpose of this investigation was to compare the glutamine concentration of the fluids, and $20 \mathrm{c.mm}$. was used throughout the investigation. Fig.' 1 Hlustrates typical results from normal fluids (1), fluids from patients in hepatic coma ( 2 and 3 ), and fluid from a patient with cirrhosis of the liver (4). In each chromatogram the very prominent band is glutamine. This was confirmed by control runs with glutamine and in some cases by two-dimensional chromatography.

Determination of Glutamine.-Fig. 2 shows the glutamine concentrations found in 18 normal fluids and in 13 fluids from patients suffering from diseases in which disturbance of liver function was not suspected. The range is from $6 \mathrm{mg}$./ $100 \mathrm{ml}$. to $14 \mathrm{mg} . / 100 \mathrm{ml}$. glutamine with the exception of one case of haemophilus meningitis, where the glutamine content was $18 \mathrm{mg} . / 100 \mathrm{ml} . ;:$ fluids from such cases have shown a pronounced increase in several amino-acids.

The glutamine concentration in nine cases of cirrhosis of the liver ranged from $16 \mathrm{mg} . / 100 \mathrm{ml}$. to $31 \mathrm{mg} . / 100 \mathrm{ml}$, , and in seven cases of hepatic coma from $30 \mathrm{mg}$. $/ 100 \mathrm{ml}$. to $54 \mathrm{mg} . / 100 \mathrm{ml}$.
In Cases 1, 2, and 6 the glutamine content of the cerebrospinal fluid was determined during a period of coma and when the patient was conscious.

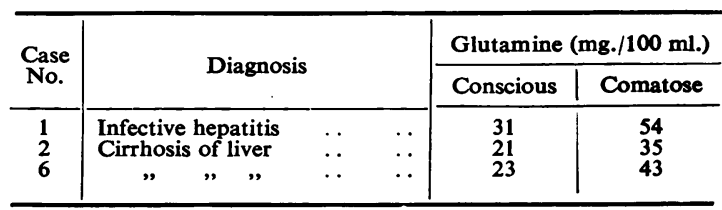

In all cases there was close agreement between the chromatographic appearance of the glutamine band and the level determined by acid hydrolysis.

\section{Discussion}

These results indicate that in cirrhosis of the liver there is an increased concentration of glutamine in the cerebrospinal fluid, and during hepatic coma this is further increased. A control series of fluids from patients in coma other than hepatic and from patients suffering from miscellaneous conditions has been analysed, and the glutamine level is not altered with the exception of the fluid from a-patient suffering from haemophilus meningitis, when a slightly raised level was found. We suggest therefore that determination of the glutamine content in the cerebrospinal fluid, which is simple to perform and speedy, may be of value in the differential diagnosis of hepatic coma. Murphy, Chalmers, Eckhardt, and Davidson (1948)

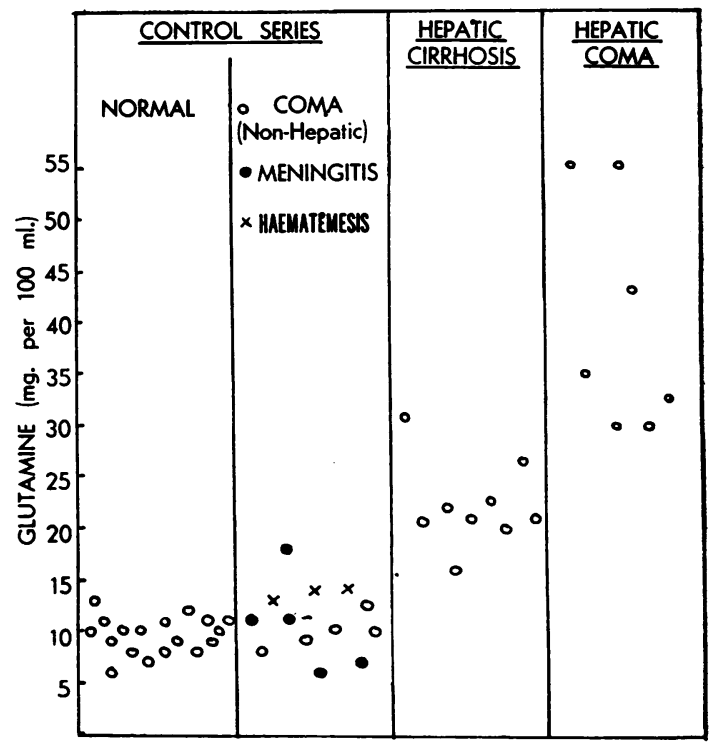

FIG. 2.-The cerebrospinal fluid glutamine values in hepatic coma, cirrhosis of the liver, and the control series. 
studied 40 patients in hepatic coma and concluded that, apart from evidence of severe hepatic failure, there was no distinctive physical sign or biochemical estimation characteristic of hepatic coma, and furthermore the biochemical findings were not significantly different in the pre-comatose stage of the disease. Our results in three cases suggest that the onset of coma is associated with a significant rise in the cerebrospinal fluid glutamine, and, in the only case in which we had an opportunity of repeating the estimation after complete recovery from coma, the glutamine level fell to a figure within the range for non-comatose cases of cirrhosis of the liver (Case 2).

The role of glutamine in the cerebrospinal fluid of patients suffering from cirrhosis of the liver and hepatic coma has not yet been elucidated. Krebs (1935) investigated the metabolism of ammonia in brain tissue and showed that it combined with glutamic acid to form glutamine. WeilMalherbe (1950) reviewed the metabolism of glutamic acid by nervous tissue and concluded that the primary function of glutamic acid was its ammonia-binding mechanism. Several recent investigations have suggested an association between raised blood ammonia levels and the development of coma in patients suffering from disease of the liver. Gabuzda, Phillips, and Davidson (1952) showed that clinical changes indistinguishable from those encountered in hepatic coma can be induced by feeding ammonium salts to patients with cirrhosis of the liver, and McDermott and Adams (1954) described stuporose attacks in a patient with a portal-caval fistula which were associated with a demonstrable rise in blood ammonia. Riddell and McDermott (1954) thought that most cases of hepatic coma were caused by ammonia intoxication and found some correlation between blood ammonia levels and neurological symptoms. On the other hand, Singh, Barclay, and Cooke (1954) could find no correlation between blood ammonia levels and the clinical state. The technical difficulties of measuring blood ammonia levels probably accounts for some discrepancy. The finding of an increased amount of glutamine in the cerebrospinal fluid in hepatic coma lends support to the suggestion that an increased concentration of ammonia in the cerebral tissues may play some part in producing this type of coma. Ajmone-Marsan, Fuortes, and Marossero (1949) thought that the pharmacological action of ammonia on the central nervous system was excitatory rather than depressant, and in the present investigation the stage of coma was ushered in by a period of confusion and excitement in five out of seven patients. Further study of glutamine levels in cerebrospinal fluid may throw light on the glutamic acid/glutamine system and determine the place of glutamic acid in the treatment of hepatic coma.

\section{Summary}

The glutamine content of the cerebrospinal fluid of patients with cirrhosis of the liver and in hepatic coma has been investigated by chromatography and by a simple assay method.

The glutamine level in cerebrospinal fluid is raised in cirrhosis and still further raised in hepatic coma. The determination of cerebrospinal fluid glutamine is advocated as a biochemical aid in the differential diagnosis of hepatic coma.

The possible relationship between ammonia intoxication and an increased cerebrospinal fluid glutamine level is discussed.

Some cases of hepatic coma were under the care of other physicians, and we wish to thank them for their co-operation in this investigation, and also Drs. A. P. Prior and J. M. Walshe for their interest and encouragement.

REFERENCES

Ajmone-Marsan, C., Fuortes, M. G. F., and Marossero, F. (1949). Electroenceph. clin. Neurophysiol., 1, 291.

Gabuzda, G. J., Phillips, G. B., and Davidson, C. S. (1952). New Engl. J. Med., 246, 124.

Giri, K. V., and Rao, N. A. N. (1952). Nature, Lond., 169, 923.

Krebs, H. A. (1935). Biochem. J., 29, 1951.

McDermott, W. V., and Adams, R. D. (1954). J. clin. Invest., 33, 1.

Murphy, T. L., Chalmers, T. C., Eckhardt, R. D., and Davidson, C. S. (1948), New Engl. J. Med., 239, 605

Prior, A. P., and Whitehead, T. P. (1953). Nature, Lond., 172, 358.

Riddell, A. G., and McDermott, W. V. (1954). Lancet, 1, 1263.

Singh, I. D., Barclay, J. A., and Cooke, W. T. (1954). Ibid., 1, 1004.

Walshe, J. M. (1951). Quart. J. Med., 20, 421.

Weil-Malherbe, H. (1950). Phvsiol. Rev., 30, 549. 